Original Article

\title{
The effects of aquatic exercise on body composition and nonspecific low back pain in elderly males
}

\author{
Khadijeh Irandoust, $\mathrm{PhD}^{1)}$, Morteza Taheri, $\mathrm{PhD}^{1)^{*}}$ \\ 1) Department of Physical Education, Imam Khomeini International University: Qazvin 34149-16818, \\ Iran
}

\begin{abstract}
Purpose] The purpose of this study was to investigate the effect of aquatic exercises on nonspecific low back pain (LBP) in elderly males. [Subjects and Methods] Thirty-two elderly men aged 65 or older were recruited and randomly allocated to two groups: aquatic training ( $3 \mathrm{~d} / \mathrm{wk}$ for $12 \mathrm{wk}$ ) or a control group. Body mass index (BMI), percentage of body fat (PBF), waist-hip ratio (WHR), and trunk muscle mass were measured before and after training. [Results] The results suggested that all obesity variables including BMI, WHR, and PBF of the aquatic training group were decreased significantly, while the trunk muscle mass of the aquatic training group was increased significantly. Furthermore, low back pain was decreased in the subjects after the intervention. [Conclusion] The water-based program improved LBP and body composition in the elderly men.

Key words: Elderly, Low back pain, Body composition
\end{abstract}

(This article was submitted Jun. 25, 2014, and was accepted Sep. 2, 2014)

\section{INTRODUCTION}

The aging process is marked by the diminishing physiological and functional capabilities in older adults. This decline in function result from the loss of muscular strength and related impaired functional mobility ${ }^{1}$, which often leads to falls, low back pain, reduced independence, and increased health-care costs ${ }^{2}$. Although the loss of muscle mass with aging (Sarcopenia) leads to muscular dysfunction ${ }^{3)}$, obesity also contributes substantially to chronic medical conditions such as low back pain ${ }^{4}$. The notable changes in body composition from maturity to senescence are well proven, even in healthy subjects. It has been well established that obesity/ overweight has side effects on low back pain ${ }^{4)}$. So an exercise therapy consisting of individually designed programs, including stretching or strengthening, may improve pain and function in chronic nonspecific low back pain ${ }^{5)}$. Numerous exercise approaches have been designed with the intention of controlling weight, improving strength, and increasing flexibility for treating low back pain ${ }^{5}$. If these exercises are done in water, the properties of water that cause resistance result in relaxation, reduce the pressure on the affected joint, and induce a feeling of exhilaration. Moreover, the combination of the buoyancy and resistance properties allow for exercise modalities in an aquatic environment that are generally too stressful on land for older populations ${ }^{6-8)}$. Although

\footnotetext{
*Corresponding author. Morteza-Taheri (E-mail: taheri
} morteza@yahoo.com)

(C2015 The Society of Physical Therapy Science. Published by IPEC Inc. This is an open-access article distributed under the terms of the Creative Commons Attribution Non-Commercial No Derivatives (by-ncnd) License $<$ http://creativecommons.org/licenses/by-nc-nd/3.0/>. it appears that water-based exercise may be a suitable exercise modality for elderly individuals, little is known about its ability to improve body composition. The interesting and distinguishing point of differences between previous studies and the presented study is the sort of exercise therapy. It was hypothesized that water-based exercises would significantly decrease abdominal and overall obesity, increase muscular strength, and consequently decrease low back symptoms in the elderly.

\section{SUBJECTS AND METHODS}

The subjects of the present study were 32 elderly men from Qazvin, Iran, who met the following selection criteria: over 65 years old, no experience of a fall in the 1 year period prior to the study, no specific disease that might influence task performance, no visual or hearing impairment, and no vestibular organ problem. All subjects agreed to actively participate in the exercises once they had been given a sufficient explanation of the tasks. Subjects were randomly allocated to two groups: aquatic training, with a mean age of $68.4 \pm 2.9$ $\mathrm{yr}(3 \mathrm{~d} / \mathrm{wk}$ for $12 \mathrm{wk})$, and a control group (67.6 $\pm 3.1 \mathrm{yr})$. The aquatic program was conducted in a heated pool (depth $1.20 \mathrm{~m}$ ) at water temperatures between $28^{\circ} \mathrm{C}$ and $30^{\circ} \mathrm{C}$ and consisted of 2 aerobic sessions and 1 session of resistance training. All sessions lasted $60 \mathrm{~min}$ and included a warm-up period (10 $\mathrm{min})$, the main program (40 $\mathrm{min})$, and a cooldown period $(10 \mathrm{~min})$. The aerobic regimen included exercises such as water walking, jogging, walking and jogging in combination with various arm movements, sidestepping, water cycling, and adapted water games (volley and basket). During resistance training, the following 8 exercises were performed: chest/upper back glide, chest back press, behindthe-back press, pivoted shoulder press (upper body) and calf 
Table 1. Body composition variables of participants before and after the intervention

\begin{tabular}{lcccc}
\hline & \multicolumn{2}{c}{ Aquatic training } & \multicolumn{2}{c}{ Control } \\
\cline { 2 - 5 } & Pre-test & Post-test & Pre-test & Post-test \\
\hline BMI $\left(\mathrm{kg} / \mathrm{m}^{2}\right)$ & $26.6 \pm 0.5$ & $25.1 \pm 0.5^{*}$ & $26.4 \pm 0.4$ & $26.3 \pm 0.5$ \\
WHR $(\mathrm{cm})$ & $0.95 \pm 0.01$ & $0.88 \pm 0.01^{*}$ & $0.91 \pm 0.01$ & $0.90 \pm 0.01$ \\
PBF $(\%)$ & $29.8 \pm 0.1$ & $27.2 \pm 0.2^{*}$ & $29.7 \pm 0.2$ & $29.2 \pm 0.1$ \\
Trunk muscle mass $(\mathrm{kg})$ & $25.4 \pm 0.7$ & $26.5 \pm 0.5^{*}$ & $25.3 \pm 0.6$ & $25.2 \pm 0.7$ \\
\hline
\end{tabular}

BMI: body mass index (calculated as weight in kilograms divided by the square of height in meters); WHR: waist/hip ratio); PBF: percent body fat

* Significant difference between the aquatic training

Table 2. The effect of water-based exercise on low back pain

\begin{tabular}{lcccc}
\hline & \multicolumn{2}{c}{ Aquatic training } & \multicolumn{2}{c}{ Control } \\
\cline { 2 - 5 } & Pre-test & Post-test & Pre-test & Post-test \\
\hline Physical symptoms & 7 & 3 & 7 & 6 \\
Psychological symptoms & 4 & 1 & 3 & 3 \\
\hline
\end{tabular}

* Significant difference between the aquatic training and control groups at $p \leq 0.05$

lifts, supported squats, outer/inner thigh scissors, and forward and backward leg glide (lower body). Each movement during resistance training was conducted using specialized equipment to increase the water resistance and the stimulus offered by the water. Before planning the exercise therapy in water, a pulse meter was used to control the heart rates of the subjects (50-70\% of maximal heart rate reserve) during the time of exercise. The subjects in the control group did not participate in any kind of exercise program. They were asked to carry out their usual daily activities throughout the study. Body mass index (BMI), percentage of body fat (PBF), waist-hip ratio (WHR), and trunk muscle mass were measured with a body composition analyzer (InBody 230, Biospace, Seoul, South Korea) before and after training. The segmental lean mass such as the trunk muscle mass can be measured with this apparatus. A simple 9-item patient questionnaire (the Keele STarT Back Screening Tool), was used to categorize back pain patients in terms of the complexity of their problem. The tool evaluates not only physical factors, such as pain radiation, severity, and related dysfunction, but also psychosocial factors that can influence outcomes, such as anxiety, depression, and pessimism. All the subjects gave written informed consent before starting the study protocol, in accordance with the Declaration of Helsinki. SPSS for Windows (version 18) was used to analyze the data. The Independent Student's t-tests was used to examine differences between the groups, with a statistical significance level of $\alpha=0.05$.

\section{RESULTS}

After the intervention, BMI, WHR, PBF, and trunk muscle mass improved significantly in the aquatic training group ( $\mathrm{p}<0.05)$ (Table 1$)$, and low back pain significantly decreased in the aquatic training group $(\mathrm{p}<0.05)$ (Table 2$)$.

\section{DISCUSSION}

The aim of this study was to assess the influence of aquatic exercises on body composition and nonspecific low back pain in elderly males. Based on our findings, WHR, PBF, BMI, trunk muscle mass, and low back pain (both physical and psychological symptoms) were significantly improved after the intervention. Since; it has been well established that obesity/overweight has side effects on low back pain ${ }^{4}$, one reason for low back pain improvement may be related to the change in body composition change in the subjects ${ }^{10)}$. Consistent with findings from other studies ${ }^{9-11)}$, we found an improvement in low back pain after aquatic exercises. Low abdominal muscular strength is considered to be a reason for low back pain; thus, increasing the muscular volume and strength may be an effective treatment strategy ${ }^{12,13)}$. Our results indicated that the trunk muscle was improved by up to $4.1 \%$ after 12 weeks aquatic training. An advantage of aquatic exercise is that it can involve the upper and lower extremities through optimal ranges of motion while minimizing joint stress. Thus, aquatic exercise can result in optimal improvement in body composition and low back pain. The present study demonstrated that an improved body composition as a result of aquatic exercise had a positive effect on nonspecific low back pain. One limitation of this study was the small number of subjects, limiting the extent to which the results can be applied to elderly men in general. Additional studies involving more subjects, a more controlled environment, and/or a different variety of psychological and physical tests are required in order to make conclusive assumptions about a larger population. The results obtained suggested that exercises in water may be one of the most useful modes of exercise for elderly individuals with low back pain. 


\section{REFERENCES}

1) Cavani V, Mier C, Muston A, et al.: Effects of a 6-week resistance training program on functional fitness of older adults. J Aging Phys Act, 2002, 10: 443-452.

2) Marcell TJ: Sarcopenia: causes, consequences, and preventions. J Gerontol A Biol Sci Med Sci, 2003, 58: M911-M916. [Medline] [CrossRef]

3) Baumgartner RN, Koehler KM, Gallagher D, et al.: Epidemiology of sar copenia among the elderly in New Mexico. Am J Epidemiol, 1998, 147 755-763. [Medline] [CrossRef]

4) Shiri R, Karppinen J, Leino-Arjas P, et al.: The association between obesity and low back pain: a meta-analysis. Am J Epidemiol, 2010, 171: 135 154. [Medline] [CrossRef]

5) Hayden JA, van Tulder MW, Tomlinson G: Systematic review: strategies for using exercise therapy to improve outcomes in chronic low back pain. Ann Intern Med, 2005, 142: 776-785. [Medline] [CrossRef]

6) Simmons V, Hansen PD: Effectiveness of water exercise on postural mobility in the well elderly: an experimental study on balance enhancement J Gerontol A Biol Sci Med Sci, 1996, 51: M233-M238. [Medline] [CrossRef]
7) Kargarfard M, Dehghadani M, Ghias R: The effect of aquatic exercise therapy on muscle strength and joint's range of motion in hemophilia patients. Int J Prev Med, 2013, 4: 50-56. [Medline]

8) Bello AI, Kalu NH, Adegoke BOA, et al.: Hydrotherapy versus land-based exercises in the management of chronic low back pain: A comparative study. J Musculoskelet Res, 2010, 13: 159-165. [CrossRef]

9) Urquhart DM, Berry P, Wluka AE, et al.: 2011 Young Investigator Award winner: Increased fat mass is associated with high levels of low back pain intensity and disability. Spine, 2011, 36: 1320-1325. [Medline] [CrossRef]

10) Dundar U, Solak O, Yigit I, et al.: Clinical effectiveness of aquatic exercise to treat chronic low back pain: a randomized controlled trial. Spine, 2009, 34: 1436-1440. [Medline] [CrossRef]

11) Maher CG: Effective physical treatment for chronic low back pain. Orthop Clin North Am, 2004, 35: 57-64. [Medline] [CrossRef]

12) Verna JL, Mayer JM, Mooney V, et al.: Back extension endurance and strength: the effect of variable-angle roman chair exercise training. Spine, 2002, 27: 1772-1777. [Medline] [CrossRef]

13) Bo Andersen L, Wedderkopp N, Leboeuf-Yde C: Association between back pain and physical fitness in adolescents. Spine, 2006, 31: 1740-1744. [Medline] [CrossRef] 